\section{Occurrence of an Exotic Oligochaete Branchiura sowerbyi Beddard, 1892, in the River Thames}

IN the course of a study of the bottom fauna of the River Thames just below Reading, a large population of Branchiura sowerbyi has been found among the roots of emergent aquatic plants such as Carex acutiformis, Acorus calamus and Schoenoplectus lacustris. Although samples have been taken from many parts of the River over a stretch of about two miles, all the specimens of Branchiura found hitherto have been from a region just below the warm water effluent of Earley power station. The distinctive characters of the worm are its large size compared with other members of the Tubificidae and the possession of filamentous gills on the mid-dorsal and mid-ventral lines of the posterior part of the body.

Branchiura sowerby was first described by Beddard ${ }^{1}$, who found it in the mud of the Victoria regia tank in the Royal Botanic Society's garden in Regent's Park, London. It was later recorded from similar warm water tanks in Hamburg ${ }^{2}$, Dublin ${ }^{3}$, Kew and Oxford $^{4}$. According to Stephenson ${ }^{5}$, it is common in India, China, Japan and Java, and occurs in the Rhone and elsewhere in southern France, possibly as a result of being introduced with plants imported into gardens on the banks of the rivers. The first person to find Branchiura in a natural habitat in Britain was Dr. P. M. Jenkin, of the Zoology Department, University of Bristol. In a recent private communication, she described her findings as follows : "A small colony has persisted for five years on the Kennet and Avon Canal. The species has now appeared for the first time in the Bradford River Avon, at a spot where collections have been made for twenty years. Temperature records stored in the University of Bristol Zoological Department show no indication of warm effluents near either of these sites. The canal is so shallow that it must freeze in the winter. The worms live in organic mud under 4-6 inches of water. They survive well in the laboratory in tubes containing tap water and some mud from their natural environment."

The population of the worms in the Thames is not a small one, as it is estimated from quantitative samples that many thousands are present. They are obviously breeding very freely, and it seems likely that the warm water effluent of the power station (maximum temperature observed, $25^{\circ} \mathrm{C}$.) is a more favourable habitat than the unheated waters of the Kennet and Avon Canal. On the other hand, the fact that the worm has appeared in a second unheated habitat suggests that it has become acclimatized sufficiently to be able to increase its numbers in a normal river. That being so, it may well spread through the river and canal system of Britain, and I would be most interested to hear of further records.

\section{K. H. MANN}

Department of Zoology,

University of Reading. July 8 .

1 Beddard, F. E., Quart. J. Micro. Sci., 33, 325 (1892).

"Michaelsen, W., "Das Tierreich, Oligochaeta" (Berlin, Friedländer, 1900).

${ }^{3}$ Southern, R., Proc. Roy. Irish Aead., 27, 119 (1909).

"Friend, H., "The Story of British Annelids" (London, 1924).

"Stephenson, J., "The Oligochaeta" (Oxford, Clarendon Press, 1930).

\section{Histochemical Study of the Nasal (Supra-Orbital) Gland of the Duck}

THE recent demonstration by Schmidt-Nielsen and co-workers ${ }^{1,2}$ that in marine birds the nasal (supraorbital) glands can, under conditions of salt loading, excrete a strongly hypertonic solution of sodium chloride has brought added significance to a study of the comparative cytology and histochemistry of these glands in progress in this department.

In the domestic duck, which has well-developed nasal glands, no histological evidence has been found to support either of the two earlier views on the nature of the secretion of these glands. One widely held opinion has been that the glands elaborate a 'serous' secretion. In the duck gland, cytoplasmic ribonucleic acid, assessed by affinity for toluidine blue and for pyronin, is notably scarce ; the secretory elements are, indeed, conspicuously eosinophilic. Moreover, 'zymogen' granules are absent. The other $v^{2}{ }^{3}$, that the gland produces a slimy (? mucous) secretion, also has no histochemical support. No mucus-secreting elements can be demonstrated by the periodic acid - Schiff technique, or with Alcian blue staining, and there is no metachromatic staining with toluidine blue.

The positive findings of the present study are (1) an extraordinary abundance of mitochondria, which appear almost to fill the cytoplasm of the secretory cells; (2) a moderate content of lipoid which is unstained by sudan III and IV, well stained by sudan black and gives a positive reaction to Baker's acid hæmatein test for phospholipids (pyridine extracted controls give a negative reaction: it seems likely that the phospholipids are mainly mitochondrial) ; (3) a very abundant blood supply ; and (4) moderate amounts of alkaline phosphatase $(3 \mathrm{hr}$. incubation, Gomori technique) in the nuclei, and minimal amounts in the cytoplasm, of cells at the extreme periphery of each gland lobule.

In their eosinophilia and high mitochondrial content, the secretory elements of the nasal gland of the duck are strongly reminiscent of the oxyntic cells of the gastric glands of mammals and of the chloride-excreting cells of the gill of euryhaline fishes, both of which are usually thought to be involved in active secretion of chloride ions.

Preliminary experiments indicate that the nasal glands of the duck are normally inactive, but that under conditions of salt loading they secrete chloride at concentrations of up to 640 m.equiv./litre-a level comparable with that reported for the cormorant ${ }^{1}$ and the penguin ${ }^{2}$.

\section{Department of Anatomy, \\ University of Glasgow. July 4.}

${ }^{1}$ Schmidt-Nielsen, K., Jörgensen, C. B., and Osaki, H., Fed. Proc., 16, 113 (1957); Amer. J. Physiol., i93, 101 (1958).

' Schmidt-Nielsen, K., and Sladen, W. J. L., Nature, 181, 1217 (1958). ${ }^{3}$ Marples, B. J., Proc. Zool. Soc., Lond., 829 (1932).

\section{Cytochromes of Nitrobacter}

A CYTOCHROME system appears to be involved in the oxidation of nitrite by Nitrobacter since, at normal temperatures, three cytochrome bands may be seen in suspensions of the cells in the presence of nitrite, but not in its absence. These are two sharp bands at $521 \mathrm{~m} \mu$ and at $550 \mathrm{~m} \mu$ and a more diffuse, less-intense band at about $589 \mathrm{~m} \mu{ }^{1}$. 